In memoriam

\title{
Ana Alice Alcântara Costa: "guerreira e forte para todo o sempre" (1951-2014)
}

\begin{abstract}
Na manhã de 26 de dezembro de 2014, depois de acirrada batalha contra um tipo de câncer dos mais agressivos, Ana Alice Alcântara Costa veio a falecer em sua residência, em Salvador, Bahia, cercada por familiares e amigas de longa data. Ana Alice deixou dois fiIhos, quatro netos, a mãe, irmãos, sobrinhos, primos e um batalhão de amigos/as, colegas, alunos/ as e ex-alunos/as, além de companheiros/as de militância em várias frentes de luta, muita gente que a amou e admirou $e$ que jamais poderá esquecê-la. Nascida em 23 de dezembro de 1951, em Caravelas, Bahia, Ana Alice passou parte

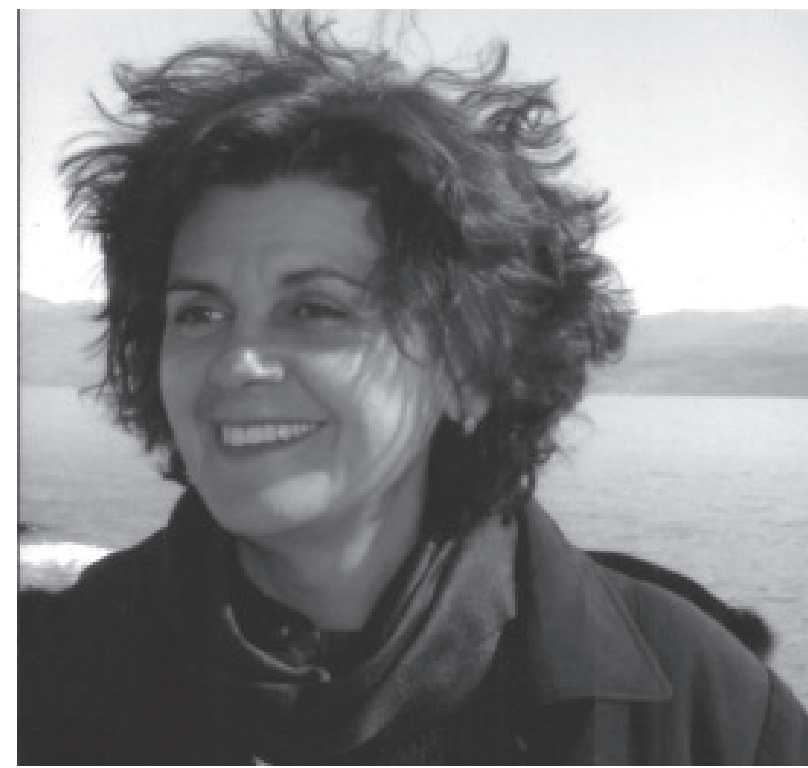
da sua primeira infância em Porto Alegre, mudando-se de volta para a Bahia em meados dos anos 1950. Filha de família de classe trabalhadora - fato do qual sempre se orgulhou -, ela cresceu no Alto do Peru, bairro popular de Salvador, concluindo o segundo grau no Colégio Estadual Severino Vieira, uma das principais arenas de mobilização estudantil na cidade nos tenebrosos anos sessenta. Foi a primeira pessoa da família a ingressar em uma universidade (em 1971), concluindo (em 1975) o curso de graduação em Ciências Sociais na Faculdade de Filosofia e Ciências Humanas da Universidade Federal da Bahia - a FFCH da UFBA -, casa para onde voltaria, poucos anos mais tarde, como membro do corpo docente.
\end{abstract}

Copyright $\odot 2015$ by Revista Estudos Feministas. 
Logo após a graduação, Ana Alice trabalhou em diferentes projetos sociais, enquanto se preparava para cursar pós-graduação em Sociologia Política no México. Dias antes de viajar, contudo, foi atropelada por um ônibus, quase na porta de sua casa. Tal como Frida Kahlo, a quem sempre admirou e com quem acabou se identificando em virtude desse acidente, ela teve que se submeter a várias cirurgias e passar quase um ano inteiro de cama, em repouso, antes de poder voltar a caminhar. Isso tudo lhe obrigou a adiar seus planos: só conseguiu chegar ao México em 1977. Logo, porém, ingressou na Universidade Nacional Autónoma de México (UNAM), onde concluiu o mestrado em 1981.

O título de sua dissertação - Avances y Definiciones del Movimiento Femenista en Brasil - bem indica o que se constituiria como seu principal objeto de pesquisa e de práxis: o feminismo. De fato, na Cidade do México, nas brechas criadas pela I Conferência Mundial da Mulher, ali realizada em 1975, surgiram vários grupos feministas, e Ana Alice participou ativamente desse processo, integrando o primeiro grupo de estudos feministas da UNAM. De volta ao Brasil, em 1981, ela viria a participar do Grupo Feminista Brasil Mulher - o BM -, a primeira entidade feminista autônoma da Bahia, que havia sido criada em 1979. No BM, Ana Alice se dedicou em especial ao Maria, Maria, jornal publicado pelo Grupo, escolando-se em 'solidariedade feminista' e construindo ali uma teia de amizades que jamais se desfez, mesmo depois que o BM deixou de atuar.

Em fins de 1981, Ana Alice prestou concurso e foi aprovada como docente a ser lotada no Departamento de Ciência Políitica da UFBA. Esse foi o primeiro concurso público para docentes de maior peso realizado nessa universidade, tendo sido aprovados mais de 400 candidatos e candidatas. No entanto, as contratações não se materializavam, dando margem ao surgimento de um movimento de concursados, que teve Ana Alice como uma de suas lideranças. Contratada, finalmente, em 1982, passou a atuar no movimento docente, uma de suas principais frentes de luta. Entre 1988-1990, foi vice-presidente da Associação dos Professores Universitários da Bahia (APUB), numa gestão encabeçada por Sofia Olzewski Filha e constituída, em quase sua totalidade, por mulheres, as quais ficaram famosas não apenas por projetar a APUB no movimento docente em nível nacional, mas também por criar um agradável espaço de sociabilidade na sede da entidade, onde docentes da UFBA se encontravam às sextas-feiras para trocar ideias, ouvir música, relaxar. Nesse período, Ana Alice participou ativamente como delegada nos encontros do Sindicato Nacional dos Docentes das Instituições de Ensino Superior (ANDES), construindo, também no movimento docente, amizades por todo o Brasil.

Mas o feminismo permaneceu como sua principal frente de militância. De fato, no início de 1983, então ainda recém-contratada pela UFBA, Ana Alice voltou de um encontro de feministas, no Rio, com uma proposta para as colegas da FFCH: criar um núcleo de estudos sobre a mulher na Bahia! Convencida de que era preciso deslanchar uma militância feminista também na academia, para além do desenvolvimento de pesquisas nesse campo que então se forjava, ela encontrou na FFCH um grupo de companheiras, professoras e estudantes do Mestrado em Ciências Humanas, que compraram essa ideia com igual entusiasmo: Alda Motta, Cecilia Sardenberg, Maria Amélia Almeida, Maria Luiza Belloni e Maria Lygia Quartim de Moraes. Assim nasceu o Núcleo de Estudos Interdisciplinares sobre a Mulher (NEIM), prestes a completar 32 anos de "teoria e práxis feministas" e "menina dos olhos" de Ana Alice.

Com efeito, desde a criação do Núcleo, Ana Alice se manteve como a grande inspiradora, articuladora e anjo protetor do NEIM e de todas e todos nós, seus integrantes, a começar pela garantia de um espaço próprio. Assim, batalhou e conseguiu uma sala para nós no casarão da $\mathrm{FFCH}$, quando tal espaço era uma verdadeira preciosidade em São Lázaro, intermediando, anos depois, um acordo entre a Direção da Faculdade e o UNICEF para a reforma de duas salas de aula abandonadas que, em tempo, com o apoio de emen- 
das parlamentares que ela também negociou, se tornariam o prédio do NEIM - em breve a ser batizado, merecidamente, como Pavilhão Ana Alice Alcantara Costa.

Ana Alice esteve também na linha de frente das negociações que transformaram o NEIM em órgão suplementar (em 1995), bem como nas que promoveram cursos de extensão e, depois, de aperfeiçoamento e especialização no campo dos estudos de gênero e feministas, culminando com a criação, em 2006, do Programa de Pós-Graduação (Mestrado e Doutorado) em Estudos Interdisciplinares sobre Mulheres, Gênero e Feminismos (PPGNEIM) e, em 2009, do Bacharelado em Gênero e Diversidade (BEGD), ambos únicos no país (ou mesmo na América Latina). E com a determinação que sempre lhe foi peculiar, deslanchou um processo, ainda em curso, para transformar o NEIM em Instituto - o INEIM -, batalhando também, incansavelmente, para a criação do Departamento de Estudos de Gênero e Feminismo, na FFCH, a ponto de postergar sua aposentadoria para as últimas semanas de vida na esperança de garantir, para o novo órgão, a vaga que iria deixar.

Na UFBA, Ana Alice percorreu a trajetória acadêmica, de Professora Auxiliar I a Associada IV (a doença não the permitiu ter o tempo suficiente para preparar e defender seu Memorial para chegar a Professora Titular), assumindo, durante sua carreira, diferentes cargos administrativos (Chefe do Departamento de Ciência Política, Coordenadora do Colegiado do Curso de Ciências Sociais, Vice-Diretora e Diretora do NEIM, Coordenadora do PPGNEIM, Diretora em Exercício da FFCH, entre outros) e de representação nas instâncias superiores da UFBA (de 2011 a 2013, representou o Corpo Docente da UFBA no Conselho Universitário, o CONSUNI). Mais recentemente, Ana Alice teve papel fundamental nas articulações com o Ministério da Educação e com a Secretaria de Políticas para Mulheres da Presidência da República (SPM-PR), que garantiram a participação do NEIM em cursos online sobre Gestão de Gênero e Raça em Políticas Públicas, aos quais, na qualidade de Coordenadora pelo NEIM, ela se dedicou até seus últimos dias, viajando pelo interior da Bahia para as aulas presenciais, mesmo apesar do estado de saúde já comprometido pela a doença. Ela coordenou, ainda, em meio às sessões de quimioterapia, o Curso de Formação em Gênero para Técnicos Legislativos, organizado pelo NEIM para a Câmara Federal, comprando brigas para garantir que nele se imprimisse uma perspectiva feminista.

Por certo, a influência de Ana Alice como feminista acadêmica se estendeu para muito além da UFBA. Entre outras atividades dessa ordem, ela integrou o grupo articulador responsável pela criação da Rede Feminista Norte e Nordeste de Estudos sobre Mulheres e Relações de Gênero (REDOR), coordenando a Rede em três diferentes períodos de gestão. Também participou da criação da Rede Brasileira de Estudos Feministas (REDEFEM), marcando presença em todos seus encontros. Integrou ainda programas internacionais de pesquisa, a exemplo do Pathways of Women's Empowerment, participando também, dentre outras atividades de cunho internacional e regional, da equipe de elaboração e monitoria dos primeiros cursos online para a América Latina, oferecidos pelo Colégio de Las Americas, por intermédio da Red Interamericana de Formación en Mujeres y Desarrollo (RIF-MD).

Em 1994, Ana Alice retornou à UNAM, na Cidade do México, como bolsista da CAPES, para realizar o doutorado e elaborar a tese intitulada La Mujer en el Poder Local en Bahia/ Brasil: la imbricación de lo publico y lo privado, que versou sobre vereadoras e prefeitas. Defendida em 1996, a tese foi publicada no Brasil, em 1998, pela Editora do NEIM com o apoio da Assembleia Legislativa do Estado da Bahia, sob o título As Donas no Poder: mulher e política na Bahia. Em 2004, também como bolsista da Capes, Ana Alice fez um estágio pósdoutoral na Universidad de Madrid, produzindo nesse período um trabalho sobre o movimento feminista no Brasil, resultado não apenas de seus estudos e pesquisas, mas também de uma reflexão a partir de sua própria vivência como militante feminista de expressão. 
Nessa qualidade, Ana Alice participou das ações que levaram à criação do Conselho Municipal da Mulher de Salvador, integrando-o como uma de suas primeiras conselheiras; esteve à frente das negociações pela criação da Delegacia Especial de Atendimento às Mulheres e do Conselho Estadual da Mulher do Estado da Bahia e na articulação do Fórum de Mulheres de Salvador; e participou com destaque nas lutas feministas pela redemocratização do país e pela inclusão dos direitos das mulheres na Constituição Federal, na Constituição do Estado da Bahia e na Lei Orgânica do Município de Salvador. De 1988 a 1989, período de gestão de Jacqueline Pitanguy à frente do Conselho Nacional dos Direitos das Mulheres (CNDM), Ana Alice atuou como Secretária Executiva, participando das ações do Lobby do Batom que garantiram uma Constituição Federal bastante progressista no tocante aos direitos das mulheres. Trabalhou, também, em parceria com organizações não governamentais (ONGs) feministas, para garantir a implementação desses direitos, participando do Conselho da Ações em Gênero e Desenvolvimento (AGENDE) e atuando como membro da Gênero e Desenvolvimento Regional (GEMDER), ambas hoje desativadas.

Na Bahia, Ana Alice aproximou o NEIM da Comissão Especial da Mulher da Assembleia Legislativa, bem como da Câmara Municipal de Salvador, prestando assessoria ainda a outros órgãos de governo, a exemplo da Superintendência de Políticas para Mulheres, da Prefeitura de Salvador, e da Superintendência de Políticas para Mulheres da SEPROMI/Bahia. Ademais, fez parte da equipe do NEIM que desenvolveu programas de assessoria em gênero para projetos de desenvolvimento rural do estado da Bahia, viajando por cidades do interior baiano, todos os meses, por cerca de três anos seguidos (de 1998 a 2000), a título de oferecer cursos a lideranças femininas, professores e extensionistas rurais, bem como oficinas para grupos produtivos de mulheres. Essa experiência aproximou Ana Alice - e com ela, o NEIM dos movimentos de trabalhadoras rurais, levando, em tempo, a uma aproximação também com o Movimento dos Sem Terra (MST). Por mais de uma década, o NEIM se responsabilizou pela organização de oficinas durante o acampamento anual de mulheres rurais, promovido pelo Diretório do MST na Bahia, uma atividade que por muitos anos envolveu docentes, pesquisadoras e estudantes da UFBA num processo de aprendizados e trocas com as mulheres do MST.

Foi também por intermédio de Ana Alice que, em meados da década de oitenta, o NEIM iniciou uma longa e profícua parceria com mulheres atuantes nos movimentos sociais urbanos, com destaque para as mulheres das periferias organizadas através da Federação de Associações de Bairros de Salvador (FABS), do Centro da Mulher Baiana (CEM) - fundado em 1983 no subúrbio como Centro da Mulher Suburbana -, da Associação de Moradores de Plataforma (AMPLA) e da Associação de Mulheres do Calafate, dentre outras associações semelhantes. Esse trabalho conjunto deu margem a diferentes ações, a exemplo da pesquisa sobre creches comunitárias, cujos resultados, publicados em livro organizado por ela, subsidiaram uma emenda popular apresentada à Câmara Municipal de Salvador por ocasião da elaboração da Lei Orgânica do Município. Em 2013, Ana Alice foi palestrante no seminário promovido pelo CEM em Arembepe, além de desfilar, junto a outras companheiras do NEIM, no "Bloco do Bacalhau", espaço de resistência e de protesto das mulheres de Plataforma, que saiu pelas ruas do bairro no Carnaval.

Nos últimos dois anos, Ana Alice se dedicou, com afinco, à criação da Revista Feminismos, trabalhando como sua editora até o último número, recém-lançado (o próximo será em sua homenagem). E mesmo com tal responsabilidade e com as inúmeras atividades de ensino, pesquisa, extensão e militância que desenvolvia, Ana Alice sempre criou tempo para escutar e aconselhar pessoas que buscavam sua ajuda, encontrando ainda, não se sabe como, energia para sair com as amigas nos fins de semana e curtir um barzinho, praia, festas de largo, a música baiana. Aliás, ela adorava dançar, adorava o Carnaval - não perdia nunca! 
Tanto que criou no NEIM o bloco "Folia Feminista", espaço de protesto e de expressão das demandas feministas, que desde 2007 sai na Mudança do Garcia, na segunda-feira de Carnaval, fazendo do lúdico também uma arena de luta. Neste Carnaval, em consonância com o espírito de luta de sua criadora, o "Folia Feminista" estará novamente nas ruas, desta feita demandando "Mais Donas no Poder" em homenagem a ela.

Ao longo de sua carreira, Ana Alice teve a felicidade de receber o merecido reconhecimento por seu trabalho, sendo agraciada com vários prêmios, entre eles, o Diploma Mulher-Cidadã Bertha Lutz, do Senado Federal, e a Medalha Maria Quitéria, da Câmara Municipal de Salvador, ambos recebidos em 2012. Em seu último encontro, realizado em finais de novembro, a REDOR prestou uma emotiva homenagem a ela, como uma das fundadoras da Rede, em reconhecimento à sua imensa contribuição para o feminismo acadêmico. Seu prematuro falecimento provocou manifestações de pesar de representantes de vários segmentos da sociedade, de movimentos sociais a autoridades governamentais, inclusive do governador eleito da Bahia, Rui Costa, e da Ministra da Secretaria de Políticas para MuIheres da Presidência da República, Eleonora Mennicucci, amiga e companheira de Ana Alice de muitas lutas nos movimentos feminista e de mulheres. Nas redes sociais onde foram postadas as notificações sobre seu falecimento, multiplicam-se ainda os depoimentos de pessoas que a conheceram e cujas vidas ela tocou. Falam do seu exemplo, da sua coragem, da sua garra. E lembram, com carinho, do seu bom humor, do sorriso largo, da solidariedade sempre em prática. Sem esquecer, é claro, das ocasionais "puxadas de orelha" em suas orientandas e orientandos - que foram muitos! - ou mesmo nas colegas e companheiras do NEIM: "Benzinha", e lá vinha ela...

Como bem expressou Márcia Macêdo, ex-aluna e colega, lembraremos de nossa amiga por "sua doçura e aspereza, seu profundo compromisso com a mudança da vida das mulheres baianas e brasileiras, sua capacidade de "enxergar a floresta" (com a agudeza de sua visão política de grande estrategista - às vezes chamada por ela de "oportunismo estratégico") e sua profunda capacidade de ser amiga e radicalmente solidária com "a pessoa", "o ser", simultaneamente, como amiga e feminista que vivia a radicalidade desse lugar". E acrescentou:

Alice era capaz dos gestos mais intensos de solidariedade política e pessoal, até afetivamente - o que só aqueles/as que puderam conviver mais perto dela tiveram a oportunidade de experienciar. Esta é a minha lembrança de nossa última vez juntas: Ana Alice, em prantos, pedindo que explicássemos aos/às alunos/as que ela não os/as abandonava, que não era por sua vontade..., porque sua vontade era continuar lutando, guerreira e forte, para todo o sempre! É assim que me lembro dela, com um profundo amor e admiração.

Por certo, Ana Alice deixa um legado de grande importância para as lutas das mulheres, pela igualdade de gênero, para o feminismo no Brasil. Deixa cursos, artigos, livros, cartilhas e vídeos nos quais defende as causas feministas. Deixa, sobretudo, seu exemplo de luta, de coragem, ao lado de lembranças de momentos felizes e de alegria que ela nos proporcionou. Por tudo isso, fará muita falta.

Para nós do NEIM, que a conhecemos de perto e, em especial, para Dona Cenira, sua mãe, Clarice e Vladimir, seus filhos, para seus netinhos e netinhas e demais familiares pessoas a quem ela tanto amou e se dedicou - ficará para sempre uma imensa saudade.

Cecilia M. B. Sardenberg Universidade Federal da Bahia 